\title{
Protonation and deprotonation induced organol hydrogelation: Bile acid derived gelators containing a basic side chain
}

\author{
Uday Maitra* and Arkajyoti Chakrabarty
}

\section{Full Research Paper}

\section{Address:}

Department of Organic Chemistry, Indian Institute of Science,

Bangalore-560012, India

\section{Email:}

Uday Maitra* - maitra@orgchem.iisc.ernet.in; Arkajyoti Chakrabarty arkajyoti82@yahoo.co.in

* Corresponding author

\section{Keywords:}

bile acid derived amines; organogelator and hydrogelator; protonation and deprotonation induced gelation; SEM and POM; thermal stability

\section{Open Access}

Beilstein J. Org. Chem. 2011, 7, 304-309.

doi:10.3762/bjoc. 7.40

Received: 19 January 2011

Accepted: 02 March 2011

Published: 10 March 2011

Guest Editor: J.-P. Desvergne

(C) 2011 Maitra and Chakrabarty; licensee Beilstein-Institut. License and terms: see end of document.

\section{Abstract}

Two bile acid derived molecules containing basic amino groups are reported to be efficient and unusual gelators of organic and aqueous solvents.

\section{Introduction}

Low molecular mass organo- and hydrogelators (LMOG) have attracted considerable attention in recent years due to their tunable physical properties, such as stimuli sensitivity. Their self-assembly in nanoscale superstructures are likely to have important implications in accessing functional nanomaterials [1]. The types of superstructures generated by the SAFINs (Self-Assembled Fibrillar Networks) include fibres, rods, and ribbons. Such self-assembled structures form mainly due to weak non-covalent interactions such as hydrogen-bonding, van der Waals forces, $\pi-\pi$ interactions, charge-transfer interactions etc. in organogels, whereas, in aqueous gels, the major driving force for aggregation is hydrophobic interaction [2]. A number of hydrogelators derived from the bile acid backbone have been described in the literature [3-5]. The earliest reports include sodium deoxycholate which forms a gel in water at $\mathrm{pH} 6.9$ [6] and calcium cholate which gels water at $\mathrm{pH} 7$ [7-9]. The facial amphiphilicity of the bile acid derivatives appears to be primarily responsible for their aggregation in water. Unlike conventional surfactant molecules, bile acid salts possess a rigid steroidal backbone, with polar hydroxyl groups on the concave $\alpha$-face and methyl groups on the convex $\beta$-face. On the other hand, relatively few bile acid derived organogelators have been reported [10-15]. Our group has previously reported chargetransfer interaction driven organogelation based on bile acid derived, and other donor molecules [16].

The present work describes efficient organo/hydrogelation by two bile acid-derived low molecular mass gelators $\mathbf{1}$ and $\mathbf{2}$ (Scheme 1) having remarkably simple structures with amino groups in the side-chain. 

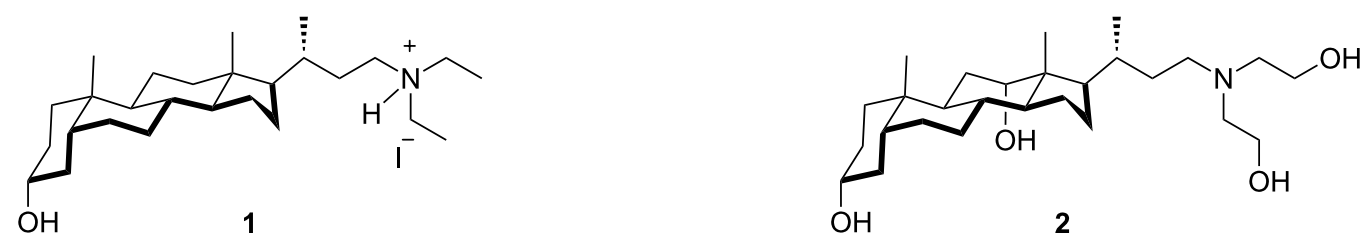

Scheme 1: Gelators 1 and 2.

\section{Results and Discussion}

Compound 1 was found to be a super gelator of organic solvents such as 1,2-dichlorobenzene and chlorobenzene and gelled these solvents at very low concentrations $(0.05 \% \mathrm{w} / \mathrm{v})$. In contrast, 2 was found to gel mixtures of aqueous organic solvents such as DMSO/water and DMF/water. Interestingly, it is the protonated amine $\mathbf{1}$ which has the organogelation property; whilst 2 must be in the neutral form for hydrogelation (Figure 1).
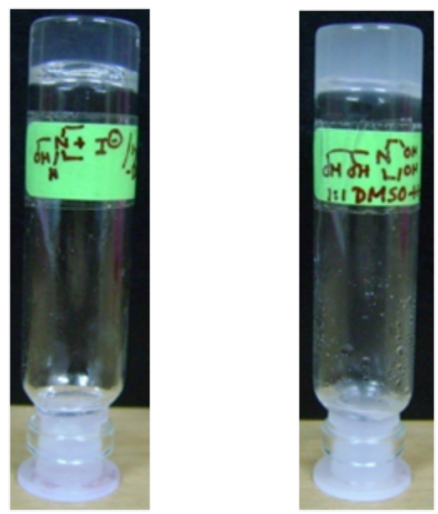

Figure 1: Photographs of the gels: 1 in 1,2-dichlorobenzene $(0.2 \% \mathrm{w} / \mathrm{v}$, left); 2 in $1: 1 \mathrm{DMSO} /$ water $(0.3 \% \mathrm{w} / \mathrm{v}$, right).

\section{(A) Gelation behaviour of 1 and 2}

The gelation tests were carried out with compounds $\mathbf{1}$ and $\mathbf{2}$ in various organic and mixtures of aqueous organic solvents (Experimental section); the results of the gelation studies are summarized in Table 1.

\section{(B) Protonation-deprotonation induced gela- tion}

The organogelator $\mathbf{1}$ was found to be a non-gelator in its neutral form, whereas when it was used as its iodide salt it formed strong gels in 1,2-dichlorobenzene and chlorobenzene. To illustrate the acid-base switching of this gel, a simple experiment was designed to show the reversible switching from gel $\rightarrow$ sol $\rightarrow$ gel of $\mathbf{1}$ in 1,2-dichlorobenzene using cresol red sodium salt as the acid-base indicator.

\begin{tabular}{lll} 
Table 1: Gelation behaviour of 1 and $2^{\mathrm{a}}$. & \\
& 1 & 2 \\
\hline Chloroform & $\mathrm{S}$ & $\mathrm{S}$ \\
Mesitylene & $\mathrm{S}$ & $\mathrm{P}$ \\
1,2-Dichlorobenzene & $\mathrm{TG}(\mathrm{CGC} 2 \mathrm{mM})$ & $\mathrm{TG}(\mathrm{W})$ \\
Chlorobenzene & $\mathrm{TG}(\mathrm{CGC} 2 \mathrm{mM})$ & $\mathrm{GP}$ \\
Benzene & $\mathrm{I}$ & $\mathrm{P}$ \\
Toluene & $\mathrm{I}$ & $\mathrm{GP}$ \\
Isopropanol & $\mathrm{S}$ & $\mathrm{S}$ \\
DMSO/water & $\mathrm{P}$ & $\mathrm{TG}(\mathrm{CGC} 5 \mathrm{mM})^{\mathrm{b}}$ \\
DMF/water & $\mathrm{S}$ & $\mathrm{TG}$ \\
MeOH/water & $\mathrm{P}$ & $\mathrm{GP}$ \\
AcOH/water & $\mathrm{S}$ & $\mathrm{S}$ \\
Acetone/water & $\mathrm{S}$ & $\mathrm{GP}$ \\
Dioxane/water & $\mathrm{S}$ & TLG \\
$\mathrm{CH}{ }_{3} \mathrm{CN} /$ water & $\mathrm{S}$ & $\mathrm{OG}$ \\
Water & $\mathrm{I}$ & $\mathrm{I}$ \\
\hline
\end{tabular}

aTG, transparent gel; TLG, translucent gel; GP, gelatinous precipitate; $\mathrm{S}$, solution; I, insoluble; $\mathrm{P}$, precipitate; OG, opaque gel; W, weak. ${ }^{b_{2}}$ formed gel in mixtures of DMSO/water (1:2 to 3:2), DMF/water (2:3 to $3: 2$ ), 1,4-dioxane/water (1:4) and acetonitrile/water (1:3).

Upon exposure to ammonia vapour, the gel (Figure 2a) formed a solution (Figure $2 b$, the solution did not form a gel on heating and cooling) with a concomitant colour change (yellow to pink). When this pink solution was exposed to HI vapour, the gel was reformed (Figure 2c, heating was required to dissolve the salt formed and the gel formed upon cooling to room temperature) with the colour turning yellow again (Figure 2d). It is important to note that cresol red turns yellow in water below $\mathrm{pH} 7.2$ and pink above $\mathrm{pH} 8.8$ [17,18]. If the pink solution (Figure 2b) was heated at $120^{\circ} \mathrm{C}$ and exposed to $\mathrm{HI}$ vapour (this was done by keeping the test tube containing the hot solution inside a sealed chamber containing conc. HI), sol to gel conversion did not require further heating and cooling.

However, for the hydrogel derived from $\mathbf{2}$, the situation was reversed. The neutral amine 2 formed a gel in 1:1 DMSO/water $(0.5 \% \mathrm{w} / \mathrm{v})$. When the gel was doped with cresol red, it developed a red colour (Figure 3a), indicating a "pH" of 7.2. However, when $10 \mu \mathrm{l}$ of $\mathrm{HI}$ (conc. HI (7 M, 57\%) was diluted 


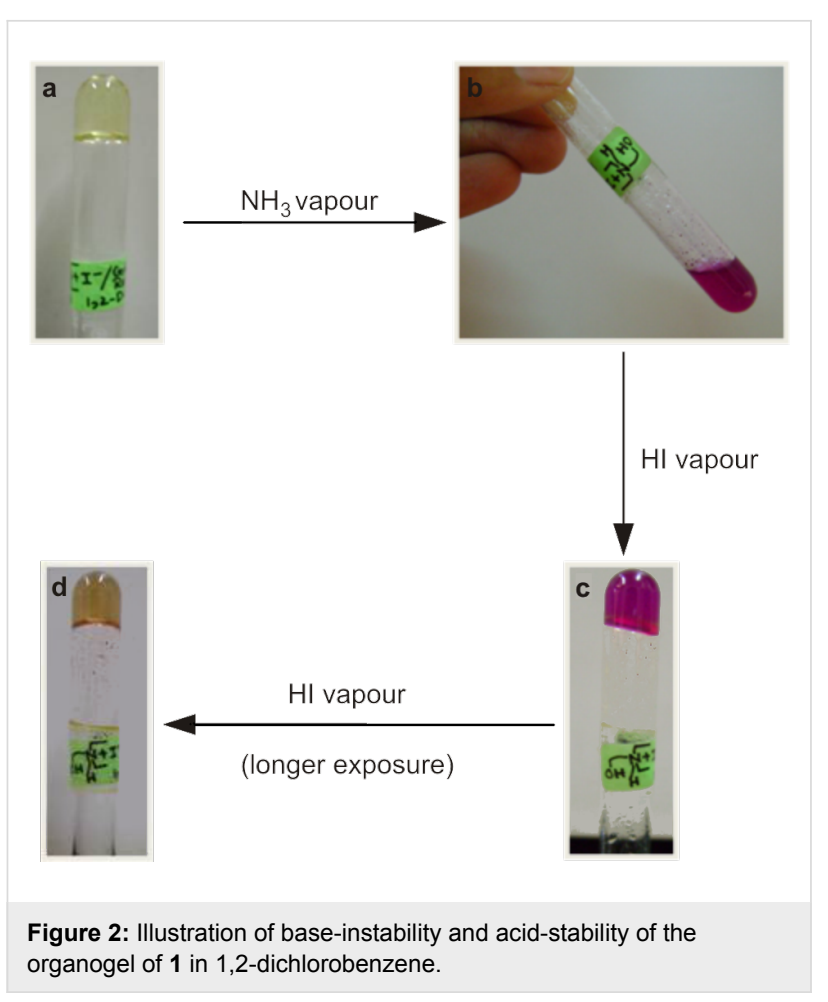

20 -fold and $\sim 0.6$ equiv of acid was used with respect to the amine) was added to the gel, the gel framework was disrupted and the solution turned yellow (Figure 3b, the gel did not reform upon heating and cooling/sonication) indicating the solution has "pH" $<7.2$. The addition of $10 \mu \mathrm{l}$ of $25 \%$ aq ammonia (13 M, 30 equiv of ammonia was used with respect to the protonated amine) triggered the sol to gel transition and this time the gel turned pink colour (Figure $3 \mathrm{c}$, heating and cooling reformed the gel).

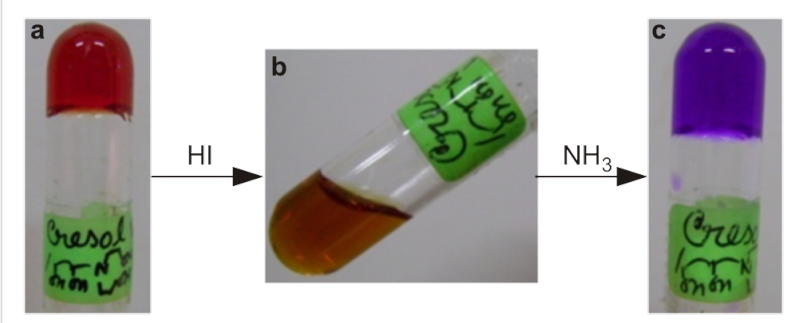

gel/cresol red

Figure 3: Acid-instability and base-stability of the hydrogel of 2 in 1:1 $\mathrm{DMSO} /$ water

\section{(C) SEM and POM characterization of the gels}

The gels showed birefringent textures under a polarizing optical microscope [19]. The organogel showed spherulitic structures [20] (where the fibres originated from nucleation centres, Figure 4a) and a highly entangled fibrillar network (Figure 4b) at higher $(1.25 \% \mathrm{w} / \mathrm{v})$ and lower $(0.25 \% \mathrm{w} / \mathrm{v})$ concentrations of gelator, respectively. SEM images showed the presence of fine fibres (diameter $<1 \mu \mathrm{m}$ ) in the organogel (Figure 4c, Figure 4d).

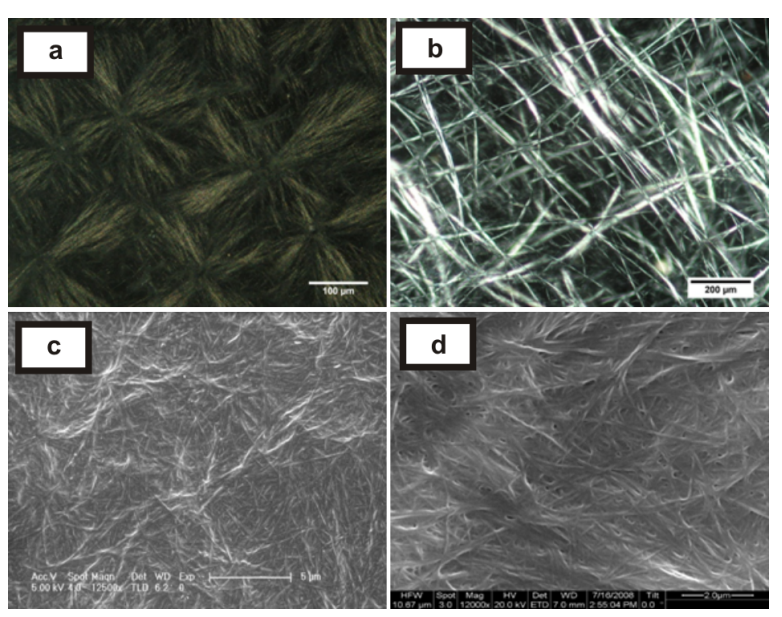

Figure 4: (a) and (b) POM images of the gels of diethylaminolithocholyl iodide 1 in 1,2 -dichlorobenzene $(1.25$ and $0.25 \% \mathrm{w} / \mathrm{v}$ of gelator, respectively); (c) and (d) SEM images of xerogels of 1 in 1,2dichlorobenzene $(0.5$ and $1 \% \mathrm{w} / \mathrm{v}$, respectively).

However, for the DMSO/water hydrogel (normally cooled), inter-connected fibres (Figure 5a) and some needle-like microcrystallites (Figure 5b) were observed under a polarizing optical microscope. Interestingly, there were two types of morphology observed in the SEM micrographs: Normally-cooled gels showed finer fibres as compared to the sonication-induced gel. The arrangement of the fibres were found to be different in the normally cooled gel (Figure 5c, 5e, 5g) in comparison to the sonication induced gel (Figure 5d, 5f, 5h) [21].

\section{(D) Thermal stability of the gels}

The concentration dependence of the thermal stability of $\mathbf{1} / 1,2-$ dichlorobenzene gel was carried out by the "inverted test-tube" method [22]. The sharp increase in melting point of the gels (Figure 6) containing 0.2 to $0.6 \% \mathrm{w} / \mathrm{v}$ of gelator could be due to the maximal interaction between solvent and gelator molecules leading to gelation [23]. There were also observable changes in the POM images as the gelator concentration was varied from 0.25 to $1.25 \% \mathrm{w} / \mathrm{v}$ (Figure $4 \mathrm{a}$ and $4 \mathrm{~b}$ ).

Thermal stability studies on the gels obtained from 2 in 1:1 DMSO/water (Figure 7) showed that normally cooled gels melted from $51-66{ }^{\circ} \mathrm{C}$ (gelator concentration 0.75 to $1.75 \% \mathrm{w} / \mathrm{v}, 12-38 \mathrm{mM}$ ). The melting profile of the sonicated samples was found to be very similar to that of the normally cooled gels. This suggests that while the sonication process after heating led to different structures of the SAFIN as illustrated in the SEM images, thermal stabilities were unaffected. 


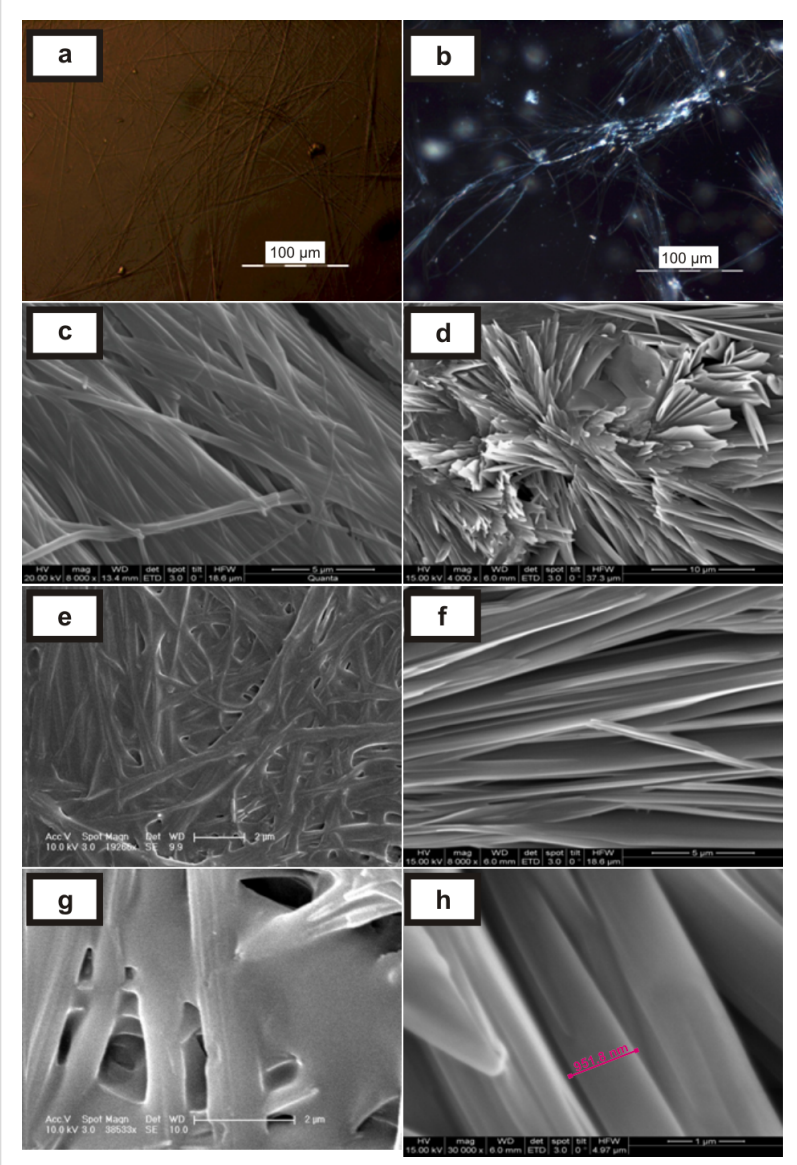

Figure 5: (a) and (b) POM images of bis(2-hydroxyethyl)aminodeoxycholane 2 gel in 1:1 DMSO/water (normally-cooled gel); (c), (e) and (g) SEM images of the xerogels (normally cooled gels); (d), (f) and (h) SEM images of the xerogels (heated and sonicated).

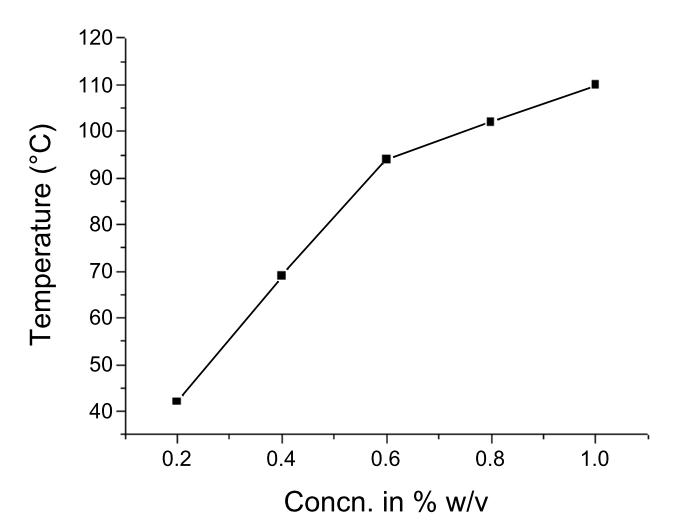

Figure 6: Gel melting profile of diethylaminolithocholyl iodide 1 gel in 1,2-dichlorobenzene.

\section{Conclusion}

In conclusion, we have demonstrated an interesting protonation and deprotonation induced gelation of an organogelator and a hydrogelator, respectively. Using cresol red as an indicator, it

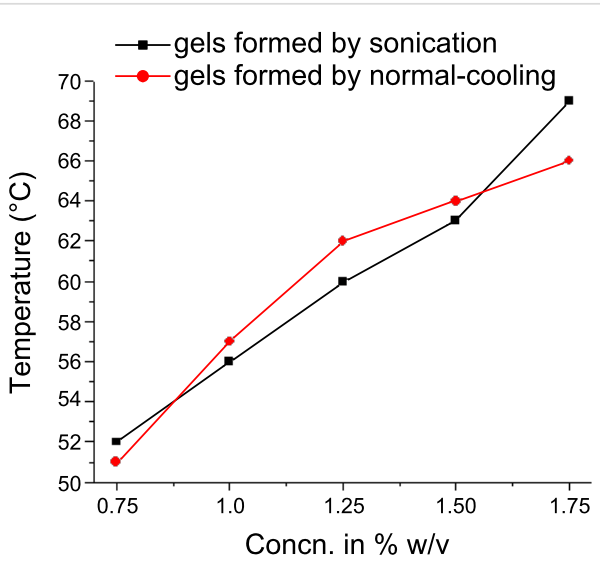

Figure 7: Gel melting profile of bis(2-hydroxyethyl)aminodeoxycholane 2 gel in 1:1 DMSO/water (normally cooled (red) and sonication-induced (black) gels).

was possible to illustrate the acid-stability and base-instability of the organogel and the acid-instability and base-stability of the hydrogel.

However, it was also found that the organogel showed high thermal stability and the nanoscale morphology represented fibres of diameters ranging from $80 \mathrm{~nm}$ to $1 \mu \mathrm{m}$. The hydrogel had comparatively lower thermal stability and showed different morphologies on sonication induced gelation and normally cooled gelation phenomenon. The hydrogel consisted of fine fibres and birefringent textures when investigated under a polarizing optical microscope.

Finally, these low molecular mass gelators which gel organic and aqueous organic solvents, represent a new class of gelators which have the ability to respond to acid-base stimuli and are potentially useful in emerging fields [24-26].

\section{Experimental \\ Materials}

The syntheses of gelators were carried out starting from lithocholic and 7-deoxycholic acids supplied by Sigma. Diethylamine was purchased from Aldrich and diethanolamine was obtained from a local supplier. Solvents were distilled prior to use.

\section{Instruments}

Olympus BX 51 polarizing optical microscope was used for recording POM images of the gels. SEM images were recorded using E-SEM Quanta machine operating at $10-20 \mathrm{kV}$ and xerogels were gold-coated with $10 \mathrm{~nm}$ thickness before recording images. For recording gel melting temperatures a Heidolph stirrer-heater was used and test tubes were sealed at the top after preparing the gels. The test tubes containing the gels were kept 
upside down in a water bath/paraffin oil bath. Temperature was increased at a controlled rate $\left(\sim 2{ }^{\circ} \mathrm{C} / \mathrm{min}\right)$. The temperature at which the gels fell under gravity was noted as the gel melting temperatures. In preparing POM samples, the gels were carefully scooped up and placed over a clean microscope slide covering the sample with a thin cover slip. In case of SEM, scooped up gels were placed over carbon tapes pasted on aluminium stubs and allowed to dry at room temperature in a desiccator connected to vacuum pump.

\section{Brief synthetic procedure}

Organogelator $\mathbf{1}$ and hydrogelator $\mathbf{2}$ were synthesized starting from lithocholic acid and deoxycholic acid, respectively, as shown in Scheme 2. Formylated lithocholic, deoxycholic acid and formyliodolithocholane, diformyliododeoxycholane were synthesized according to reported procedures $[27,28]$.

\section{Synthesis of compound 1}

$3 \alpha$-Formyloxy-5 $\beta$-23-iodo-24-norcholane ( $0.50 \mathrm{~g}, 1.03 \mathrm{mmol})$ was dissolved in diethylamine $(10 \mathrm{~mL}, 96 \mathrm{mmol})$ and stirred at $50{ }^{\circ} \mathrm{C}$ for $18 \mathrm{~h}$. After removing the volatiles, the crude product was purified by column chromatography on silica gel $(2.5 \mathrm{~cm} \times$ $10.0 \mathrm{~cm}$ ) with $5-10 \% \mathrm{EtOH} / \mathrm{CHCl}_{3}$ as eluent to yield $0.53 \mathrm{~g}$ $(97 \%)$ of the salt. The product was re-precipitated with $\mathrm{CHCl}_{3} /$ hexane (1:20) and separated by centrifugation. This process was repeated twice to obtain the pure salt $(0.40 \mathrm{~g}, 74 \%)$. m.p. $272-276{ }^{\circ} \mathrm{C} .[\alpha]_{\mathrm{D}}{ }^{24}: 36$ (c 2.00, EtOH). ${ }^{1} \mathrm{H}$ NMR $(400 \mathrm{MHz}$, $\left.\mathrm{CDCl}_{3}\right): \delta 3.64(\mathrm{~m}, 1 \mathrm{H}), 3.23-2.97$ (br m, 6H), 2.03-1.52 (steroidal $\mathrm{CH}_{2}$ ), $1.48(\mathrm{t}, 6 \mathrm{H}, J=7.2 \mathrm{~Hz}), 1.42-1.10$ (steroidal $\left.\mathrm{CH}_{2}\right), 0.99(\mathrm{~d}, 3 \mathrm{H}, J=5.6 \mathrm{~Hz}), 0.92(\mathrm{~s}, 3 \mathrm{H}), 0.65(\mathrm{~s}, 3 \mathrm{H})$. ${ }^{13} \mathrm{C}$ NMR $\left(75 \mathrm{MHz}, \mathrm{CDCl}_{3}\right): \delta 71.7,56.4,55.6,49.4,47.3$, $42.8,42.0,40.3,40.1,36.4,35.8,35.3,34.5,34.3,30.5,28.8$, $28.5,27.1,26.3,24.1,23.3,20.7,18.7,12.0,8.8$. IR (KBr): $\widetilde{v}_{\max } 3457,2927,2860,1457,1040 \mathrm{~cm}^{-1}$. HRMS (ESI): Calcd. for $\mathrm{C}_{27} \mathrm{H}_{50} \mathrm{NO}^{+}[\mathrm{M}+\mathrm{H}]^{+}$404.3887; Found 404.3892. Anal. calcd. for $\mathrm{C}_{27} \mathrm{H}_{50} \mathrm{NOI}$ : C, 61.00, H 9.48, N, 2.63. Found: C, 61.14, H, 9.50, N, 3.10.

${ }^{1} \mathrm{H}$ NMR of the neutral form of compound 1 i.e. $\mathrm{C}_{27} \mathrm{H}_{49} \mathrm{NO}$ showed the following pattern: ${ }^{1} \mathrm{H} \mathrm{NMR}\left(400 \mathrm{MHz}, \mathrm{CDCl}_{3}\right)$ : $\delta$ $3.63(\mathrm{~m}, 1 \mathrm{H}), 2.57-2.36$ (br m, 6H), 1.98-1.10 (steroidal $\mathrm{CH}_{2}$ ), 1.04 (t, 6H, $J=7.2 \mathrm{~Hz}$ ), 0.94-0.92 (s, d merged, 6H), 0.64 (s, $3 \mathrm{H})$.

\section{Synthesis of compound 2}

$3 \alpha, 12 \alpha$-Diformyloxy-5 $\beta$-23-iodo-24-norcholane (0.74 g, $1.56 \mathrm{mmol})$ was stirred with diethanolamine $(15 \mathrm{~mL}$, $157 \mathrm{mmol}$ ) at $80{ }^{\circ} \mathrm{C}$ for $24 \mathrm{~h}$. The reaction mixture was diluted with $150 \mathrm{~mL}$ of $\mathrm{CHCl}_{3}$ and washed with water $(2 \times 50 \mathrm{~mL})$ in a separatory funnel $(250 \mathrm{~mL})$. The organic layer was dried over anhydrous $\mathrm{Na}_{2} \mathrm{SO}_{4}$. The crude product was purified by column chromatography on silica gel $(2.5 \mathrm{~cm} \times 10.0 \mathrm{~cm})$ with $20-40 \%$ EtOH/ $\mathrm{CHCl}_{3}$ as eluent. The column purified product was passed through a column of basic alumina $(0.7 \mathrm{~cm} \times 16 \mathrm{~cm})$ to remove traces of acidic impurities. The neutral amine was obtained in $66 \%$ yield $\left(0.46\right.$ g). m.p.: $155-156^{\circ} \mathrm{C}$. $[\alpha]_{\mathrm{D}}{ }^{29}: 44$
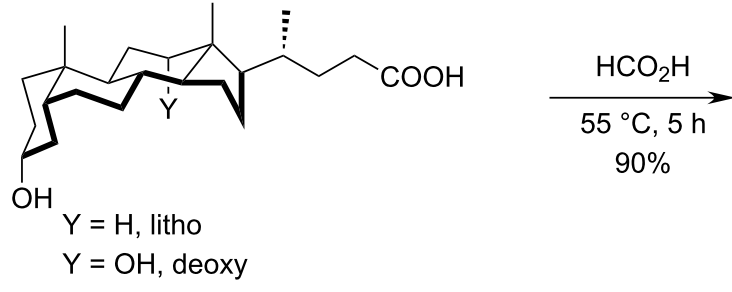

diethylamine, rt, $18 \mathrm{~h}$

or, diethanolamine $95^{\circ} \mathrm{C}, 18 \mathrm{~h}$

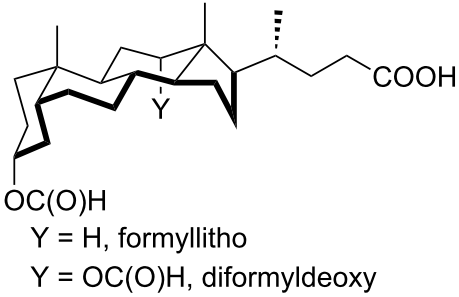

\begin{tabular}{c|c}
$\mathrm{Pb}(\mathrm{OAc})_{4}, \mathrm{I}_{2}, \mathrm{CCl}_{4}$ \\
$78^{\circ} \mathrm{C}, 4.5 \mathrm{~h}$
\end{tabular} \mid Yield: $75 \%$

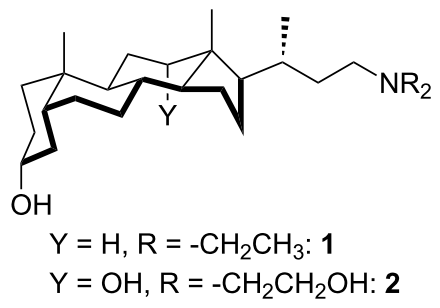

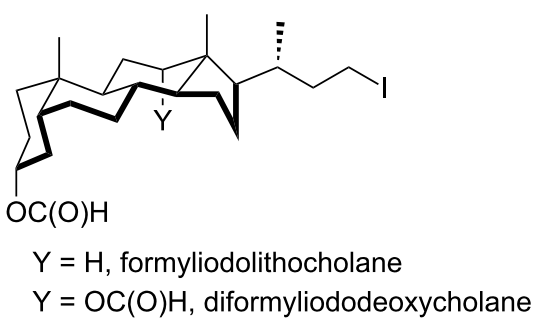


(c 2.00, EtOH). ${ }^{1} \mathrm{H}$ NMR (300 MHz, $\mathrm{CDCl}_{3}$ ): $\delta 3.98$ (br s, $\left.1 \mathrm{H}\right)$, $3.65-3.58(\mathrm{~m}, 5 \mathrm{H}), 2.74-2.47(\mathrm{~m}, 6 \mathrm{H}), 1.00(\mathrm{~d}, J=6.6 \mathrm{~Hz}, 3 \mathrm{H})$, $0.91(\mathrm{~s}, 3 \mathrm{H}), 0.68(\mathrm{~s}, 3 \mathrm{H}) .{ }^{13} \mathrm{C} \mathrm{NMR}\left(75 \mathrm{MHz}, \mathrm{CDCl}_{3}\right): \delta 73.1$, 71.7, 59.4, 56.1, 52.0, 48.2, 47.2, 46.5, 42.1, 36.4, 36.0, 35.2, $34.1,33.6,32.4,30.4,29.6,28.6,27.7,27.1,26.1,23.6,23.1$, 17.9, 12.7. IR (KBr): $\widetilde{v}_{\max } 3375,2935,2863,1470,1448,1045$ $\mathrm{cm}^{-1}$. LRMS (ESI): Calcd. for $\mathrm{C}_{27} \mathrm{H}_{49} \mathrm{NO}_{4} \mathrm{Na} 474$. Found 474. Anal. calcd. for $\mathrm{C}_{27} \mathrm{H}_{49} \mathrm{NO}_{4}$ : C, 71.80, H, 10.93, N 3.10. Found: C, 71.45, H, 10.82, N, 3.20.

\section{Gelation procedure}

The gelation tests were performed by dissolving compound $\mathbf{1}$ in 1,2-dichlorobenzene by heating at $120^{\circ} \mathrm{C}$ and then allowing to cool to room temperature to form the gel. The gels formed very fast (2-15 min depending upon the gelator concentration). A translucent gel formed when the gelator 2 was dissolved in DMSO followed by addition of water at rt. If the resulting solution was heated at $110^{\circ} \mathrm{C}$ to yield a transparent solution, it took 5-10 min to form an almost transparent gel upon cooling to rt. However, a transparent gel was obtained when the hot solution was sonicated for $35-40 \mathrm{~s}$.

\section{Acknowledgements}

We thank the department of Science \& Technology, New Delhi for financial assistance (J. C. Bose Fellowship to UM). AC thanks the CSIR, New Delhi for a fellowship. The Institute Nanoscience Initiative is thanked for providing electron microscope facilities.

\section{References}

1. Banerjee, S.; Das, R. K.; Maitra, U. J. Mater. Chem. 2009, 19, 6649. doi:10.1039/b819218a

2. Weiss, R.; Terech, P. Molecular Gels: Materials with Self-Assembled Fibrillar Networks; Springer, 2006.

See pp 449-450 and pp 613-614.

3. Maitra, U.; Mukhopadhyay, S.; Sarkar, A.; Rao, P.; Indi, S. S. Angew. Chem., Int. Ed. 2001, 40, 2281. doi:10.1002/1521-3773(20010618)40:12<2281::AID-ANIE2281>3.0.CO ;2-L

4. Sangeetha, N. M.; Balasubramanian, R.; Maitra, U.; Ghosh, S.; Raju, A. R. Langmuir 2002, 18, 7154. doi:10.1021/la025569n

5. Maitra, U.; Babu, P. Steroids 2003, 68, 459. doi:10.1016/S0039-128X(03)00051-5

6. Rich, A.; Blow, D. M. Nature 1958, 182, 423. doi:10.1038/182423a0

7. Schryver, S. B. Proc. R. Soc. London, Ser. B 1914, 87, 366. doi:10.1098/rspb.1914.0023

8. Schryver, S. B. Proc. R. Soc. London, Ser. B 1916, 89, 176. doi:10.1098/rspb.1916.0004

9. Schryver, S. B.; Hewlett, M. Proc. R. Soc. London, Ser. B 1916, 89, 361. doi:10.1098/rspb.1916.0022

10. Nonappa; Maitra, U. Soft Matter 2007, 3, 1428. doi:10.1039/b711010c

11. Hishikawa, Y.; Sada, K.; Watanabe, R.; Miyata, M.; Hanabusa, K. Chem. Lett. 1998, 27, 795. doi:10.1246/cl.1998.795
12. Nakano, K.; Hishikawa, Y.; Sada, K.; Miyata, M.; Hanabusa, K. Chem. Lett. 2000, 29, 1170. doi:10.1246/cl.2000.1170

13. Willemen, H. N.; Vermonden, T.; Marcelis, A. T. M.; Sudhölter, E. J. R. Eur. J. Org. Chem. 2001, 2329. doi:10.1002/1099-0690(200106)2001:12<2329::AID-EJOC2329>3.0.C O;2-N

14. Willemen, H. N.; Vermonden, T.; Marcelis, A. T. M.; Sudhölter, E. J. R. Langmuir 2002, 18, 7102. doi:10.1021/la025514l

15. Willemen, H. M.; Marcelis, A. T. M.; Sudhölter, E. J. R.; Bouwman, W. G.; Demé, B.; Terech, P. Langmuir 2004, 20, 2075. doi:10.1021/la035041y

16. Maitra, U.; Kumar, P. V.; Chandra, N.; D'Souza, L. J.; Prasanna, M. D.; Raju, A. R. Chem. Commun. 1999, 595. doi:10.1039/A809821B

17. Greenwood, N. N.; Earnshaw, A. Chemistry of the Elements, 2nd ed.; Butterworth-Heinemann: Oxford, UK, 1997.

18. The Merck Index, 7th ed.; Merck \& Co: Rahway, New Jersey, USA, 1960; pp $370 \mathrm{ff}$.

19. Sangeetha, N. M.; Bhat, S.; Choudhury, A. R.; Maitra, U.; Terech, P. J. Phys. Chem. B 2004, 108, 16056. doi:10.1021/jp047272z

20. Huang, X.; Terech, P.; Raghavan, S. R.; Weiss, R. G. J. Am. Chem. Soc. 2005, 127, 4336. doi:10.1021/ja0426544

21. Bardelang, D.; Camerel, F.; Margeson, J. C.; Leek, D. M.; Schmutz, M.; Zaman, B.; Yu, K.; Soldatov, D. V.; Ziessel, R.; Ratcliffe, C. I.; Ripmeester, J. A. J. Am. Chem. Soc. 2008, 130, 3313. doi:10.1021/ja711342y

22. Clavier, G. M.; Brugger, J.-F.; Bouas-Laurent, H.; Pozzo, J.-L. J. Chem. Soc., Perkin Trans. 2 1998, 2527. doi:10.1039/a803302a

23. Tata, M.; John, V. T.; Waguespack, Y. Y.; McPherson, G. L. J. Am. Chem. Soc. 1994, 116, 9464. doi:10.1021/ja00100a008

24. Ishi-i, T.; Shinkai, S. Top. Curr. Chem. 2005, 258, 119. doi:10.1007/b135554

25. Palui, G.; Banerjee, A. J. Phys. Chem. B 2008, 112, 10107. doi:10.1021/jp801657h

26. Chung, J. W.; An, B.; Park, S. Y. Chem. Mater. 2008, 20, 6750. doi:10.1021/cm8019186

27. Babu, P.; Maitra, U. Steroids 2005, 70, 681. doi:10.1016/j.steroids.2005.03.008

28. Bhat, S.; Maitra, U. Tetrahedron 2007, 63, 7309. doi:10.1016/j.tet.2007.03.118

\section{License and Terms}

This is an Open Access article under the terms of the Creative Commons Attribution License (http://creativecommons.org/licenses/by/2.0), which permits unrestricted use, distribution, and reproduction in any medium, provided the original work is properly cited.

The license is subject to the Beilstein Journal of Organic Chemistry terms and conditions: (http://www.beilstein-journals.org/bjoc)

The definitive version of this article is the electronic one which can be found at: doi:10.3762/bjoc. 7.40 